\title{
FY20 Report for Instrumentation Development for the Transient Testing Program
}

C. Jensen, K. Tsai, A. Fleming Idaho National Laboratory

September 2020

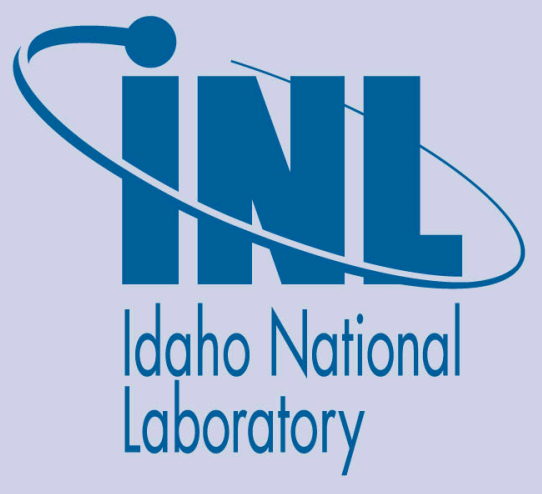

The INL is a U.S. Department of Energy National Laboratory operated by Battelle Energy Alliance 


\section{DISCLAIMER}

This information was prepared as an account of work sponsored by an agency of the U.S. Government. Neither the U.S. Government nor any agency thereof, nor any of their employees, makes any warranty, expressed or implied, or assumes any legal liability or responsibility for the accuracy, completeness, or usefulness, of any information, apparatus, product, or process disclosed, or represents that its use would not infringe privately owned rights. References herein to any specific commercial product, process, or service by trade name, trade mark, manufacturer, or otherwise, does not necessarily constitute or imply its endorsement, recommendation, or favoring by the U.S. Government or any agency thereof. The views and opinions of authors expressed herein do not necessarily state or reflect those of the U.S. Government or any agency thereof. 
INL/EXT-20-59951 Rev. 0

\title{
FY20 Report for Instrumentation Development for the Transient Testing Program
}

\author{
C. Jensen, K. Tsai, A. Fleming \\ Idaho National Laboratory
}

September 2020 Idaho National Laboratory Idaho Falls, Idaho 83415

http://www.inl.gov

Prepared for the

U.S. Department of Energy

Office of NA

Under DOE Idaho Operations Office

Contract DE-AC07-05ID14517 



\begin{abstract}
This yearly report provides a summary of accomplishments carried out under funding from the Department of Energy (DOE) Nuclear Technology Research and Development (NTRD) program for in-pile instrumentation supporting the transient testing program in FY20. These activities were performed in support of cross-cutting transient testing experiment objectives. In this year, specific instrument $R \& D$ has been a lesser priority to years past, with complementary instrumentation R\&D being ramped up under the DOE Advanced Sensors and Instrumentation Program. The primary focus of the work in FY20 pertain to defining a process and system, developed over the past several years, for developing, qualifying, and deploying instrumentation in in-pile experiments. The purpose of this report is to provide a summary of these outcomes and be a reference for researchers that are interested in developing in-pile instrumentation, with a particular emphasis on the Transient Reactor Test (TREAT) facility for deployment.
\end{abstract}


INL/EXT-20-59951 Rev. 0 
INL/EXT-20-59951 Rev. 0

\section{CONTENTS}

ABSTRACT iii

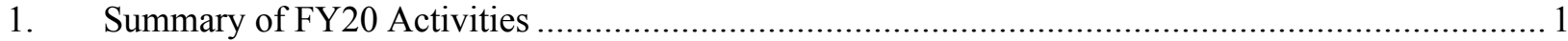

1.1 Establishing Guidelines for Development and Qualification of In-Pile

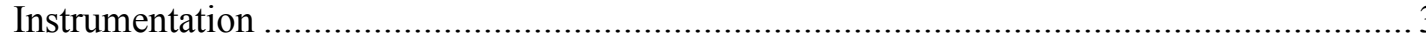

1.2 Method for Testing Instrumentation Concurrently to Ongoing Operations in the

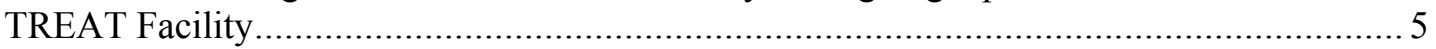

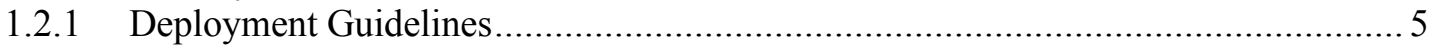

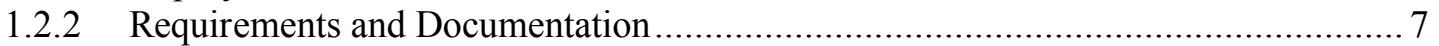

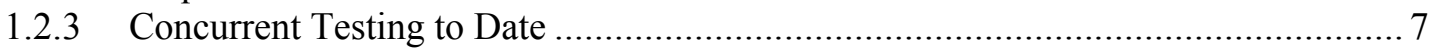

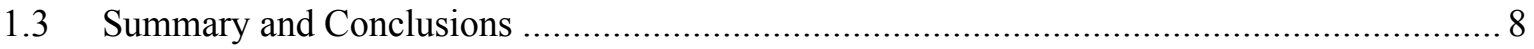

Appendix A - Overview Slides of Approach to Testing Instrumentation Concurrently with

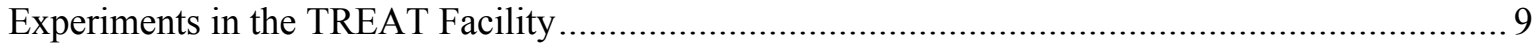

Appendix B - Pictorial Overview Concurrent Testing Hardware and Layout in the TREAT

Facility

\section{FIGURES}

Figure 1. Cover page for Guide GDE-947.

Figure 2. Drawing of (a) flux/fission wire holder, (b) sensor holder, and (c) Top-down view of fuel assemblies and cooling channel.

Figure 3. Cutaway and plan view of TREAT reactor and floor plan describing cable routing from core to data acquisition system outside of the radiological buffer area (RBA) (Figure taken from ).

Figure 4. Example of concurrent testing sensors and locations overlay with TREAT core map with relative peak-to-average flux ratios 


\section{FY20 Report for Instrumentation Development for the Transient Testing Program}

\section{Summary of FY20 Activities}

Extensive instrumentation testing and experimentation in the Transient Reactor Test (TREAT) facility at Idaho National Laboratory (INL) has been accomplished over the past 2.5 years. These experiments have provided a wealth of understanding related to the performance of a variety of in-situ measurement devices. This work represents a crucial component of a new generation of transient irradiation testing of nuclear fuels and materials supporting a variety of Department of Energy (DOE) Office of Nuclear Energy (NE) and nuclear energy industry programs and needs. A successful transient testing program hinges on a well-coordinated and innovative instrumentation development and qualification program to support future objectives ${ }^{\mathrm{a}}$. With this goal, the fuel safety research program is actively pursuing the Research, Development, and Demonstration (RD\&D) of several cross-cutting, advanced instrument technologies to meet near-term experiment programmatic goals while establishing the base measurement capabilities (state-of-the-art) for next-generation experimentation.

In contrast to previous reports focused more on technical outcomes, this report provides a focused summary of the process of developing and qualifying in-pile instrumentation, with a focus on experiment applications, and a more detailed overview the approach to testing instruments in the TREAT Facility. Current plans for next year do not include specific support for in-pile instrumentation but will happen under individual experiment (e.g. RIA, LOCA, THOR) projects. The technical outcomes of ongoing RD\&D programs for multiple key instrumentation technologies supporting near-term experimental objectives. The activities fall into three categories: temperature, mechanical behaviors, and flux and energy deposition. Building on success from last year, notable activities have focused on in-pile deployment of several advanced instrumentation capabilities that are important to near-term experimental goals. Previous instrumentation reports are found in ${ }^{\mathrm{b}, \mathrm{c}, \mathrm{d}}$.

The testing accomplished via concurrent instrument testing (as passive companions to ongoing experiments and operations) has played, and will continue to play, a crucial role in developing methods to interpret sensor signals, troubleshoot instrument performance, and ultimately lead to qualification of instruments that support experiments. The overall process and methodology have become a flagship demonstration of instrumentation deployment that benefits in-pile experimental programs and the advanced reactor community at large by providing in-pile testing as a primary component of R\&D efforts. Examples of devices that have been irradiated in the TREAT facility in irradiation-effects testing as well as in experimental devices include thermocouples, linear voltage differential transducers, a variety of optical fibers, distributed temperature sensors, infrared pyrometry, novel electro-impedance sensor, selfpowered detectors, fission chambers, electronics - in and near the core, commercial sensors, etc.

This report provides a summary of two primary accomplishments for in-pile instrumentation deployment:

\footnotetext{
a Jensen, C., "Strategic Plan for Instrumentation Development and Qualification for the Transient Testing Program," INL/LTD17-43144 Rev. 2, August 2019.

b Jensen, C., et al., "FY19 Report for Instrumentation Development for the Transient Testing Program," INL/EXT-19-56000, September 2019.

c Jensen, C., et al., "FY18 Report for Instrumentation Development for the Transient Testing Program," INL/EXT-18-515613, September 2018.

d Jensen, C., et al., "FY17 Report for Instrumentation Development for the Transient Testing Program," INL/EXT-18-43444, September 2017.
} 
INL/EXT-20-59951 Rev. 0

- Development of Guidelines for Developing and Qualifying In-Pile Instrumentation.

- Overview of the concurrent instrumentation approach and established process for the TREAT Facility

The following provides and overview of these two subjects. 


\subsection{Establishing Guidelines for Development and Qualification of In- Pile Instrumentation}

During FY20, guidelines were developed and published to support wide ranging instrumentation development and qualification needs. This effort was supported by the Nuclear Energy Enabling Technology (NEET) Advanced Sensors and Instrumentation (ASI) program as well as the Nuclear Technology Research and Development (NTRD) Advanced Fuels Campaign (AFC). These guidelines provide a framework for successfully transforming a measurement concept to a functional technology that provides reliable data, including testing and qualification in accordance with accepted quality assurance procedures to ensure suitability of their intended end use. It is also written to provide flexibility in the process to support a variety of development needs ranging from development from concept to incorporating commercial sensors in experiments. The guidelines have been published in INL document GDE-947, "Guidelines for Developing and Qualifying Instrumentation Systems at Idaho National Laboratory."

The full guide document is available upon request to appropriate INL representatives. The cover page for GDE-947 is shown in Figure 1. To provide more context, the Scope and Purpose sections of the document are shared here from GDE-947:

66

\section{SCOPE}

Guidelines are provided for developing and qualifying nuclear sensor and instrument systems at Idaho National Laboratory (INL) as a way of ensuring quality products and adherence to quality assurance (QA) best practices. This document provides a framework for performing research, development, demonstration, and deployment for sensor systems, including testing and qualification in accordance with accepted QA procedures to ensure suitability of their intended end use. The guidelines are generalized so as to apply to all sensor systems being developed at INL; however, there is a particular focus on sensors being developed to obtain in-pile data for determining how advanced nuclear fuels perform under a variety of transient conditions in INL test reactors. Further, these guidelines are applicable to devices developed to collect fuel and material performance data obtained for a variety of customers, including customers using data to support licensing of technology through the Nuclear Regulatory Commission (NRC).

The document is written from an engineering perspective and provides reactor instrument system development procedures for INL engineering organizations. This procedure is not meant to contain detailed QA procedures for interfacing organizations, such as quality-, procurement-, test-reactor-, or regulatory-related organizations. This document supports INL's overall QA program, which meets ASME NQA-1 and International Standards Organization (ISO) quality standards (Ref. 1). Assurance is given that all aspects of the instrumentation $R \& D$ are performed by properly qualified engineers, that applicable activities and results are well-documented, and that the documentation stands ready for review or auditing. The QA program most applicable to INL's sensor development mission is NQA-1 Subpart 4.2 (Ref. 2), which conveys a graded approach to sensors and data developed for $R \& D$ experimental conditions. These requirements are shown in Section 4. The pertinent parts of these QA procedures are summarized in these guidelines for developing and qualifying new reactor instrumentation.

An overview of the scope, purpose, and application of these guidelines is shown in Sections 1-3, and a list of pertinent $Q A$ requirements is given in Section 4. A summary description of the engineering activities performed in accordance with INL's Conduct of Engineering standards [Ref. 3 ] are shown in Section 5. A list of acronyms is given in Section 6, and references are provided in Section 7. Appendix A gives a detailed breakdown of potential activities supporting instrument $R \& D$ for qualification purposes. 
INL/EXT-20-59951 Rev. 0

Appendix B contains a detailed description - along with examples - of how to quantify uncertainties related to measurement systems and their applications.

\section{PURPOSE}

This document is based on accepted $Q A$ and procedural standards for product development and is intended as a useful reference guide for INL instrumentation R\&D. It references NASA, NQA-1, the ISO metrology, and nuclear industry standards but simplifies and adapts them to enhance their pertinence to the INL sensor system development process. The guidelines are primarily aimed at providing procedures for producing designs and performance data for fuels and materials, thereby supporting their licensing by NRC. The guidelines are general, yet broad enough to be adapted for any sensor system being developed in INL's Measurement Science Department. They provide a solid basis for characterizing and categorizing sensor systems developed and tested by INL. The guideline document also aligns with current INL engineering and testing procedures, and with established INL work controls and processes. ,

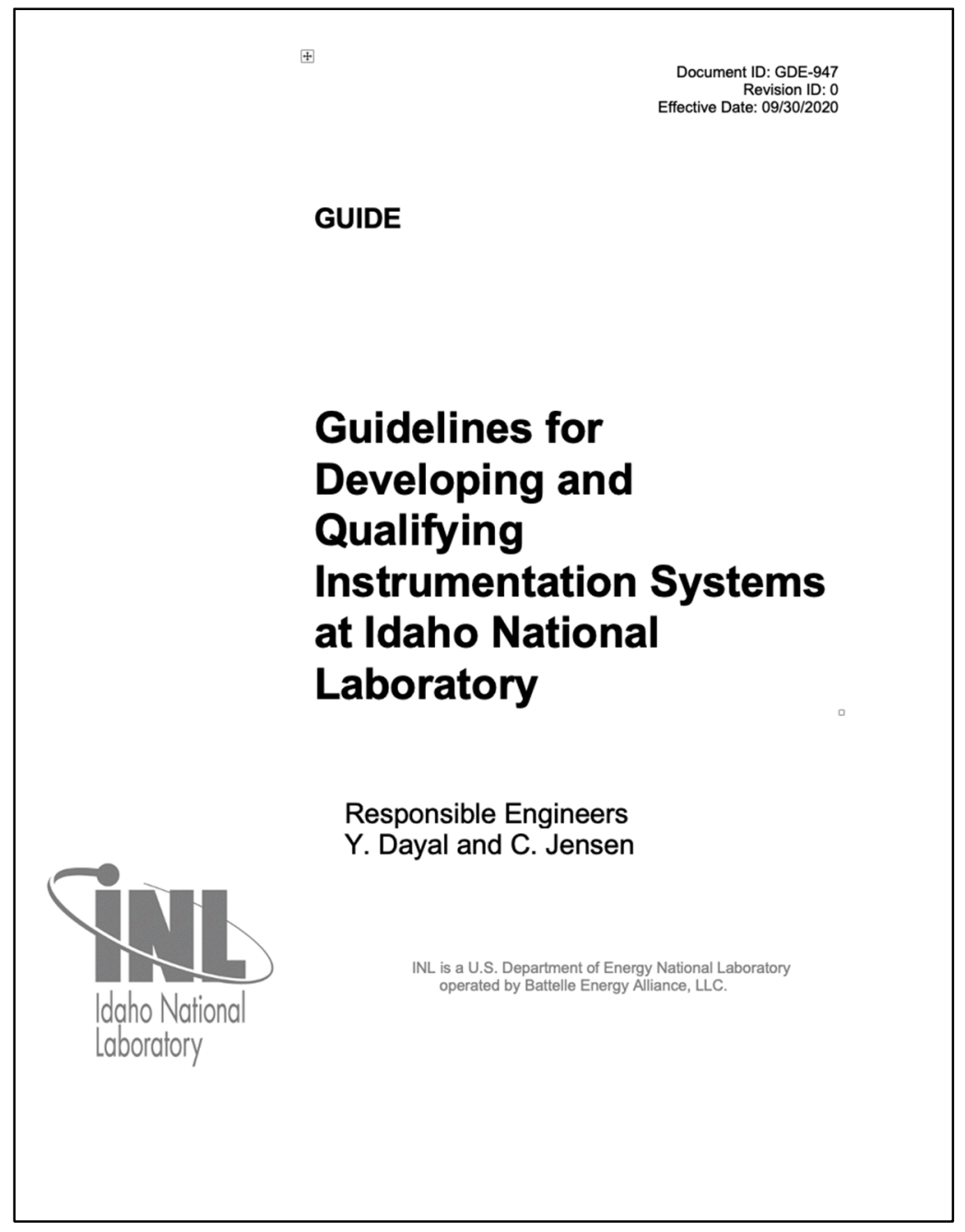

Figure 1. Cover page for INL guide document GDE-947. 


\subsection{Method for Testing Instrumentation Concurrently to Ongoing Operations in the TREAT Facility}

Irradiation testing of in-pile instrumentation in the Transient Reactor Test (TREAT) facility is a unique and crucial component of sensor qualification for experiment deployments. The included instrument technologies are of strategic importance for achieving near- and long-term, cross-cutting experiment objectives. The primary purpose of isolated sensor testing in the TREAT facility is to evaluate the impacts of the irradiation environment to in-pile sensors and to demonstrate sensor integration within the TREAT facility (e.g. cable routing, data acquisition, etc.). These evaluations and demonstrations of sensor performance within a nuclear facility are important components towards sensor qualification for expanded applications. The overall strategy of sensor deployments covered in this document is for concurrent installation and measurements performed as independent accompaniment of other planned experiments and operations at the TREAT facility, also termed "concurrent testing." The unique strategy has been developed over the past 2.5 years as an exemplary cooperation between instrument engineers and engineers at the TREAT facility. The approach has proven very successful in terms of R\&D output and overall efficiency that has accelerated the in-situ instrumentation prowess at the TREAT facility manifest in dozens of experiments over a short period of time. The scope of this section is to provide guidelines and address the documentation requirements for sensor deployment within TREAT as a component of concurrent testing. Appendix A presents a detailed overview of the concurrent testing process and the following sections describes some key features in more detail. Appendix B provides a pictorial representation of the relevant hardware and TREAT Facility layout.

\subsubsection{Deployment Guidelines}

The design and placement of the sensors in concurrent testing enables adjoined deployment in the reactor accompanying unrelated reactor activities with negligible effect on reactor operation and experiment objectives. In this mode, the concurrently tested instruments are basically "along for the ride," without having input on a given prescribed reactor transient design. The concurrent testing plans are subject to potential concerns of operations, reactor engineering, programmatic interests, and, of course, must show compliance with the TREAT facility Safety Analysis Report. Thus, implications pertaining to all of these must be considered carefully and, to date, has been shown to be very successful due to excellent cooperation and coordination between all of these interests. Sensors deployed for concurrent testing occupy cooling channels between fuel assemblies. Specific TREAT monitor wires/sensor holders were designed and are used to enable insertion and removal of sensors from TREAT air cooling channels by suspending sensors inside the 0.65 " square gap between fuel assemblies as shown in Figure 2. 


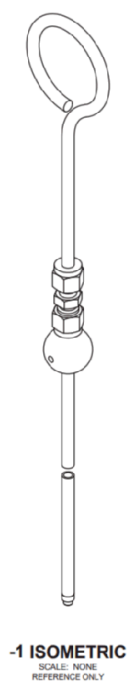

(a)

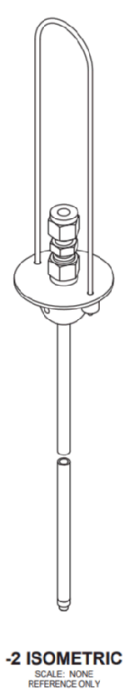

(b)

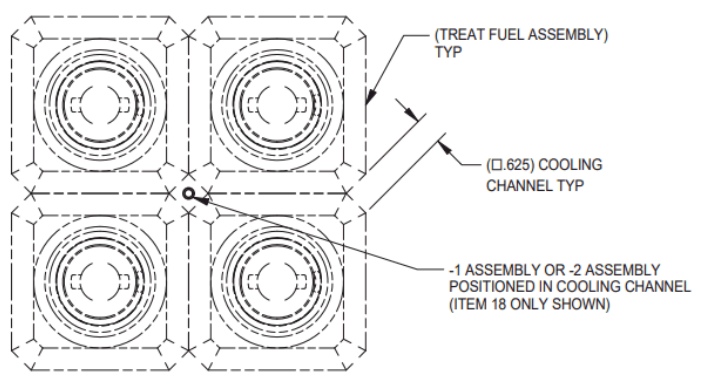

TYPICAL INSTALLATION

ONLY 4 FUEL ASSEMBLIES SHOWN SCALE: $1 / 2$
REFERENCE ONLY

(c)

Figure 2. Drawing of (a) flux/fission wire holder, (b) sensor holder, and (c) Top-down view of fuel assemblies and cooling channel.

These instrument inserts benefit from the open core access (no coolant, no pressure vessel) of the TREAT facility and relatively short lead wire runs, and, a major enabling capability, a flexibly accessible "Experimenter's Room" for data acquisition systems. Cabling from sensors in the cooling channels are routed through a hole in the removable shield block above the core center to reactor top corner (Figure 3 segment number 2) for connection to supplemental electronics such as preamplifiers if needed. Additional cablings further route the signal to data acquisition systems (DAS) in the adjacent Experimenter's room outside of the radiological buffer area. The experimenter's room contains standard 120VAC power plugs. A closed network is available for accessing experimental DAS from the control room in a separate building. Additionally, a 5V trigger is supplied to the experimenter's room for time synchronizing with the reactor data during transients. 


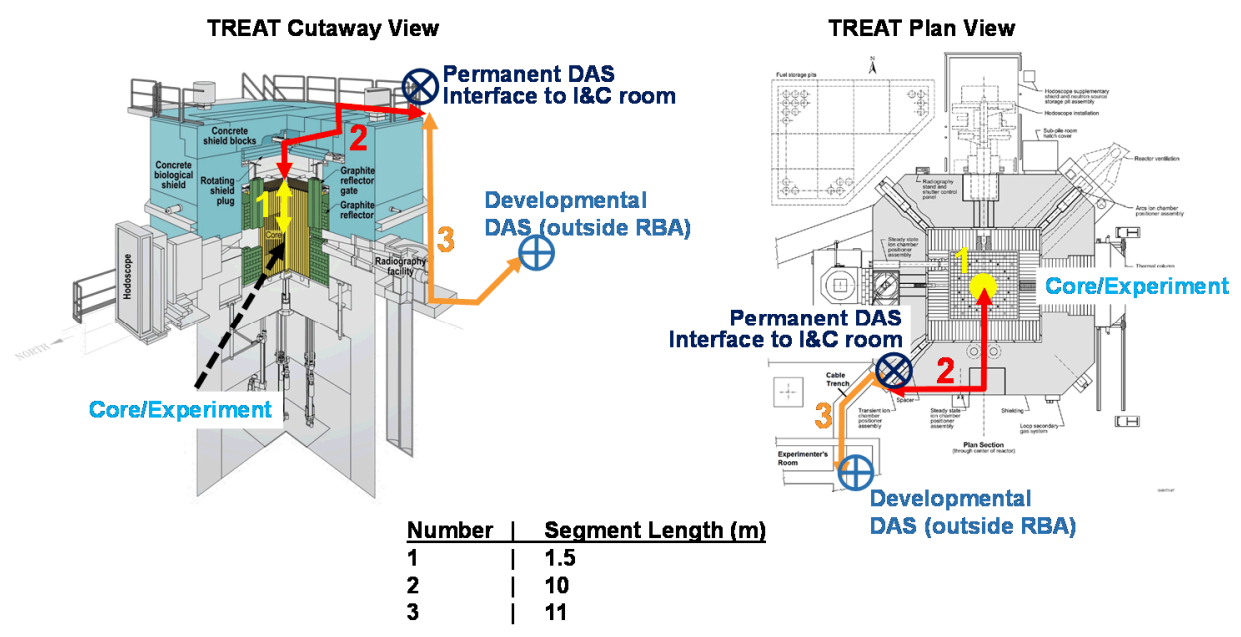

Figure 3. Cutaway and plan view of TREAT reactor and floor plan describing cable routing from core to data acquisition system outside of the radiological buffer area (RBA) (Figure taken from ${ }^{\mathrm{e}}$ ).

\subsubsection{Requirements and Documentation}

Concurrent testing of sensors and the use of dosimetry falls under the requirements listed by the INL procedure: SP-50.3.4.3-TREAT EXPERIMENT RELATED HARDWARE EVALUATION REQUIREMENTS. The purpose the document are as follows:

"This procedure establishes the process for evaluating hazards associated with experiment related activities that do not meet the definition of EXPERIMENT from TS420 and, therefore, do not require an Experiment Safety Analysis (ESA)(see def.) at the Transient Reactor Test (TREAT) Facility. These activities may include flux measurements with or without a calibration vehicle, instrument testing and qualification, and hardware reactivity worth determinations. Completion of the evaluation and authorization to perform the activity will be documented in the Operations Test Plan (OTP)."

In compliance with the requirements listed in the procedure, additional analysis such as neutronic and thermal analysis are performed. A more detailed overview of this process and all resulting documents that enable concurrent testing is given in the attached presentation in Appendix A.

\subsubsection{Concurrent Testing to Date}

The concurrent testing approach was drafted during the TREAT restart project and began in the $1^{\text {st }}$ transient executed to support external experimenters in April 2018. Since then, concurrent instruments have participated in nearly every transient. Under the concurrent testing strategy, a total of 14 different sensor types have been irradiated with some sensors experiencing up to 110 transients of wide ranging power profiles and magnitudes. An example of the concurrent testing layout during an experiment campaign is shown in Figure 4.

e Jensen, C., et al., "FY19 Report for Instrumentation Development for the Transient Testing Program," INL/EXT-19-56000, September 2019. 


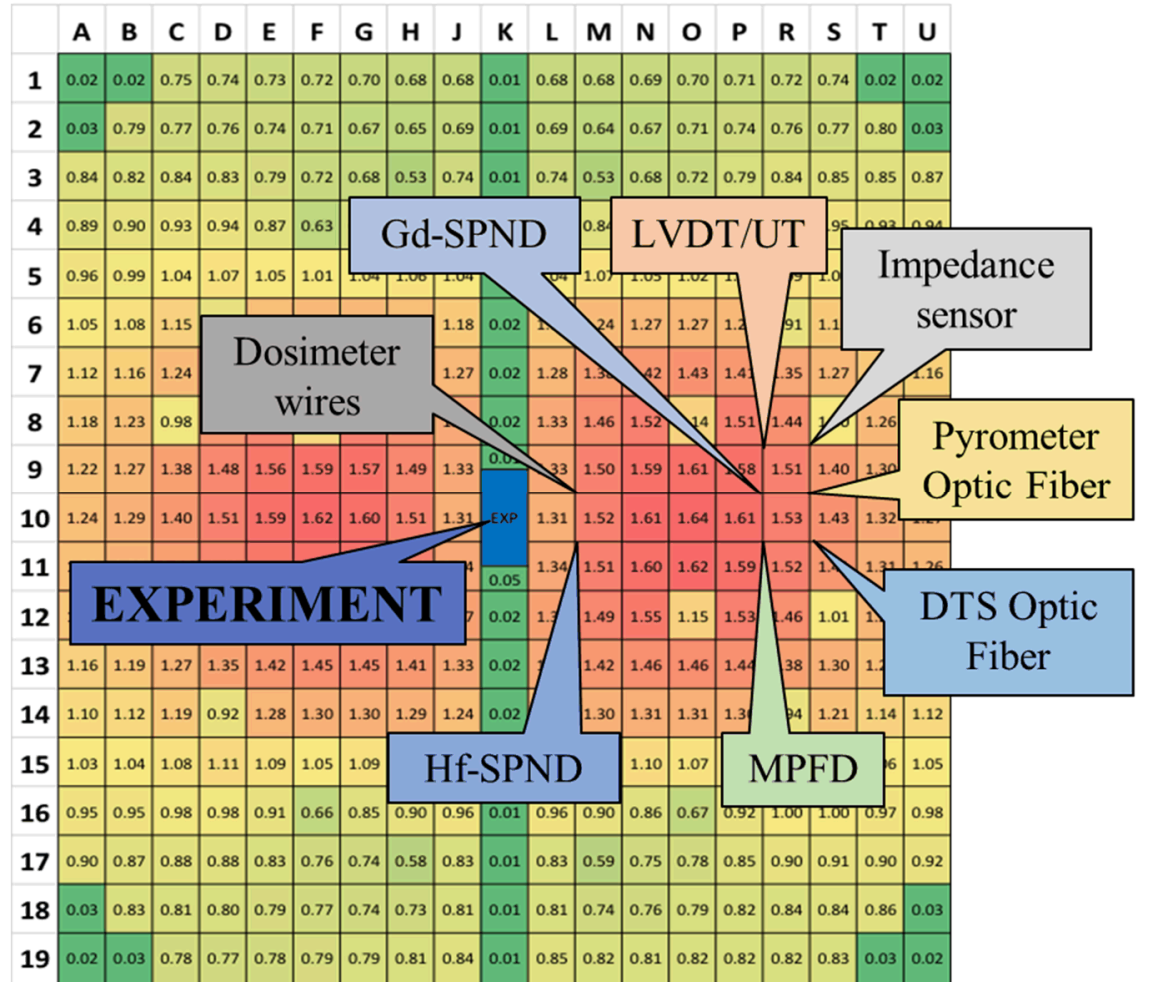

Figure 4. Example of concurrent testing sensors and locations overlay with TREAT core map with relative peak-toaverage flux ratios.

\subsection{Summary and Conclusions}

Concurrent testing has proven to be an invaluable tool supporting TREAT experiment outcomes but also the development and qualification of in-pile instruments for wide ranging applications. A process has been developed and implemented that facilitates efficient instrument deployments with near continuous opportunity for in-pile testing. Appendix A provides more a detailed overview of the current concurrent testing process that will support facility, experimenter, instrument developer, and advanced reactor instrumentation needs. 
Appendix A - Overview Slides of Approach to Testing Instrumentation Concurrently with Experiments in the TREAT Facility

Kevin Tsai

Measurement Science Dept.

Idaho National Laboratory

\section{TREAT Concurrent Testing Documentation}

\section{PVI Idaho National Laboratiory}

\section{Outline}

- Introduction

- Data Package (DP)

- Concurrent Testing Overview

- Additional Documents

- ECAR

- TEV

- FRM-1738

- Travelers 


\section{Introduction}

- Data packages used for TREAT Experiments

- Phase 1: Conceptual Design

- Phase 2: Preliminary Design

- Phase 3: Final Design

- Special Requirements

- Handling

- Radiography

- Shipping, Storage, and Disposition

- Experiment Checks After Installation

- Experiment Operation

- Core Loading

- Steady State Conditions

- Hodoscope operating parameters

- Transient operating parameters

- Conditions for performing Irradiation

- TREAT data requirements

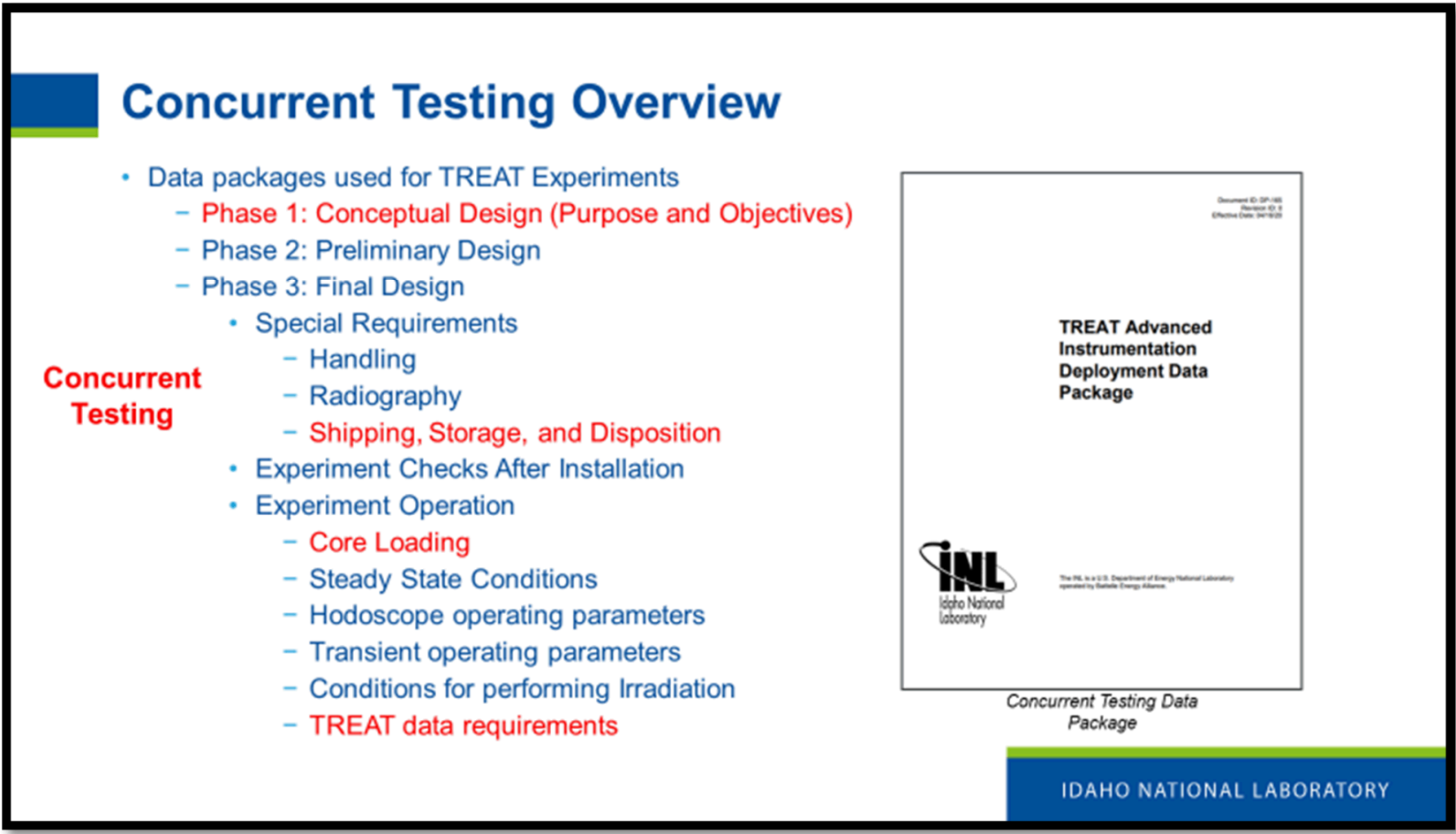




\section{Concurrent Testing Overview: Purpose and Objective}

- Irradiation testing to qualify sensors for experiment deployments

- Identify impacts of radiation environment to sensors

- Demonstrate sensor integration

- Support ongoing physics testing and characterizing reactor performance

- "Concurrent" to other ongoing experiments

- Accompanying other reactor activities

- "Other" activities specify the transients

- Concurrent testing does not specify transients

- Negligible effect on reactor operation and experiment objectives

- $\Delta k_{\text {eff }}(\%)<0.05$ for all changes in core loading including the experiment

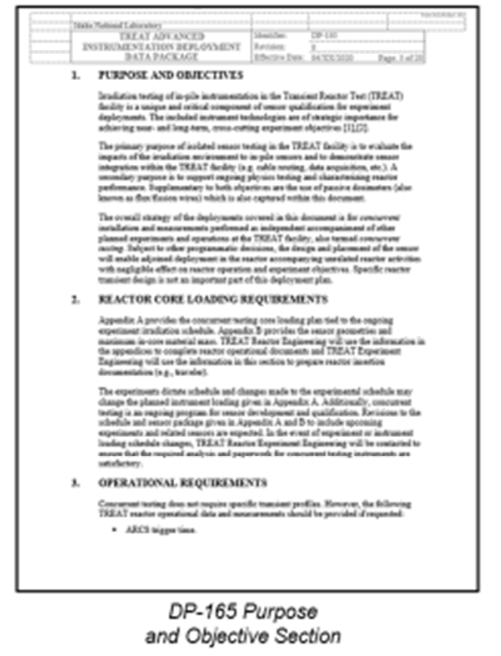

IDAHO NATIONAL LABORATORY

\section{Concurrent Testing Overview:} Shipping, Storage, and Disposition

- All sensors must have a disposition plan following irradiation

- Disposal via WGS or transfer to another facility

- Requires an estimation of source terms

- Source terms estimated from neutronic analysis

- Generally captured in an ECAR

- ECAR-4098 "TREAT Monitor Wire Holder Physics Analysis"

- ECAR-4693 "TREAT Legacy Fission Wire Physics Analysis"

- ECAR-5015 "TREAT Physics Analysis Results for the Ultrasonic Thermometer Calorimeter"

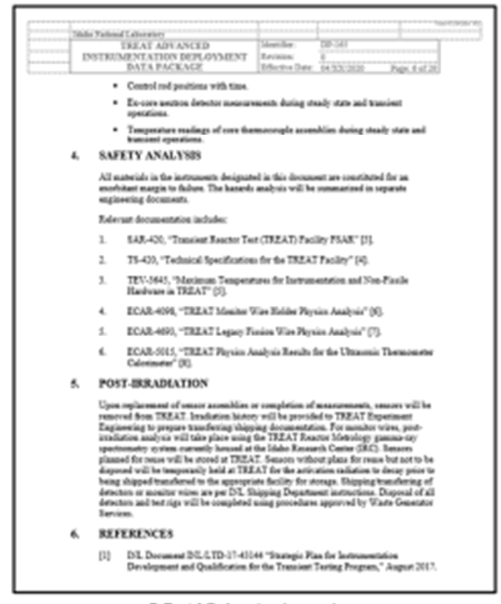

DP-165 Analysis and Post-Irradiation Section 


\section{Concurrent Testing Overview:} Core Loading

- Designate desired sensor location related to experiment irradiations

- MARCH-SERTTA

- CHF-B/C

- SIRIUS-2

- Possible sensor locations:

- Cooling channel numbers

- A-1-1

- Experiment series

- MIMIC-N positions

- Experiment position

- A through L

- Trial transients only

- Help generate travelers (FRM-2568) for sensor insertion/removal

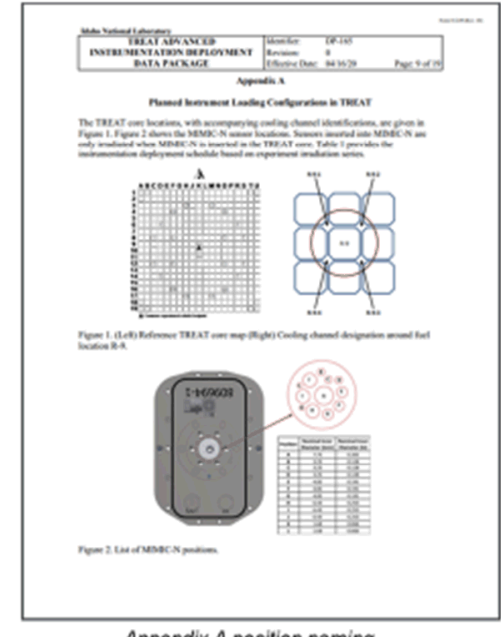

Appendix A position naming description

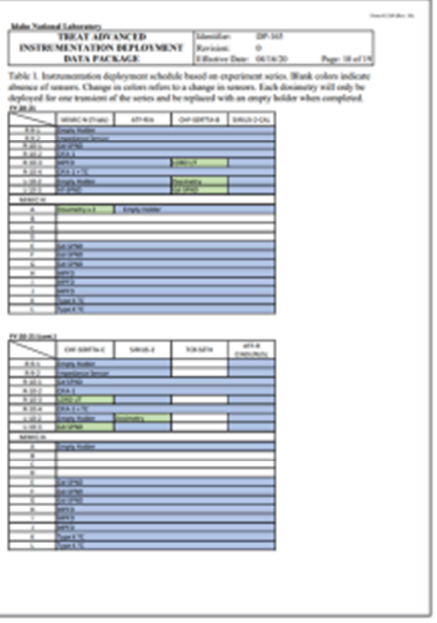

Appendix A Sensor Location

IDAHO NATIONAL LABORATORY

\section{Concurrent Testing Overview: Core Loading}

- Includes sensor geometry and material mass required for modeling

- Overview sketch

- Holder description

- Geometry

- Maximum In-Core Mass/Sensor

- Allows TREAT Reactor Engineer analyze for experimental ECAR and to generate a core configuration form (FRM-1738)

- Works with previously mentioned ECARs to generate source terms and peak in-core temperature

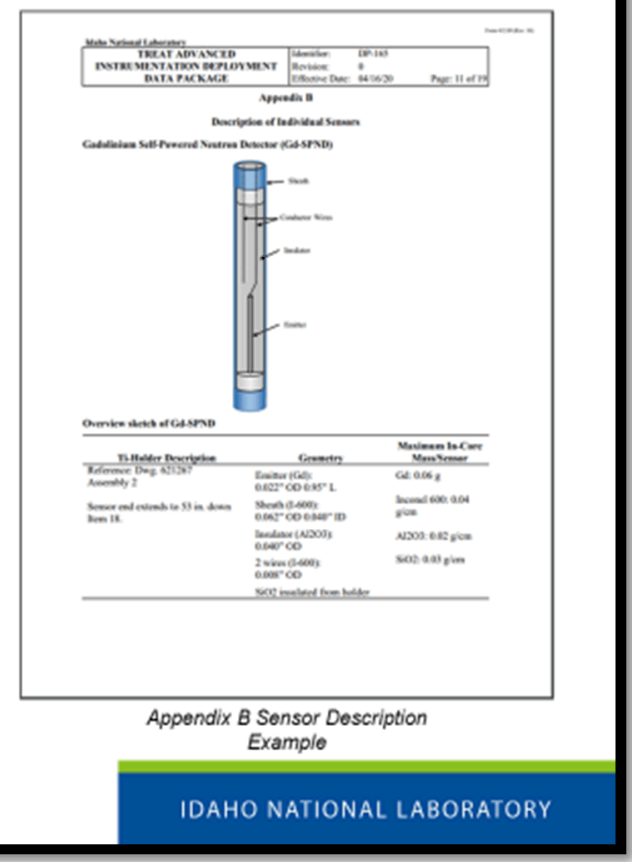




\section{Additional Documents}

- Engineering Calculation and Analysis (ECAR)

- Model core loading and calculate $\Delta k_{e f f}(\%)$ between a NED core and an experimental core.

- Can include source terms and heating rates

- Technical Evaluation (TEV)

- An extension of ECAR

- Thermal analysis for safety

- Travelers (FRM-2568)

- Used by Operations

- Designate core loading of sensors and associated approvals

- Safety Engineer

- Reactor Engineer

- Sponsor

- SS/SRO

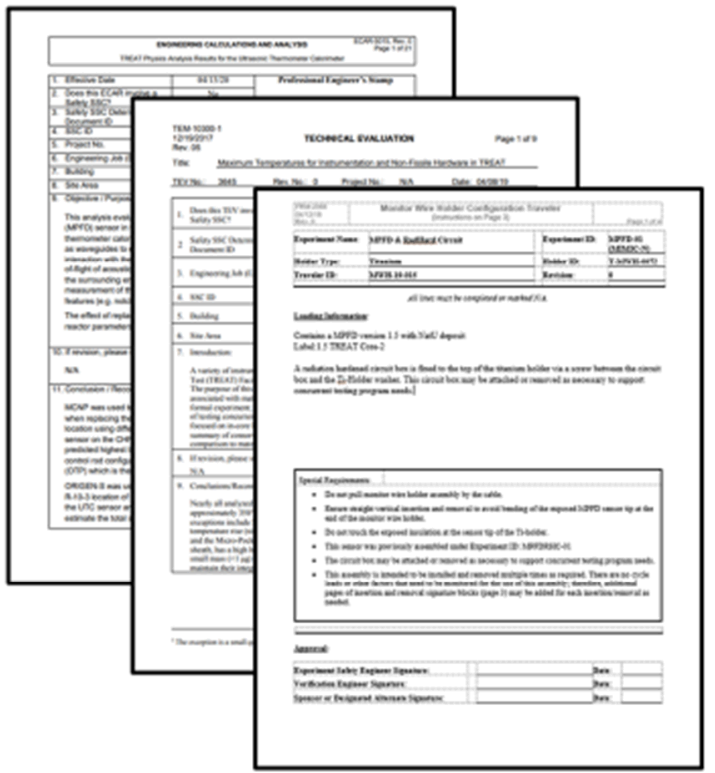

IDAHO NATIONAL LABORATORY

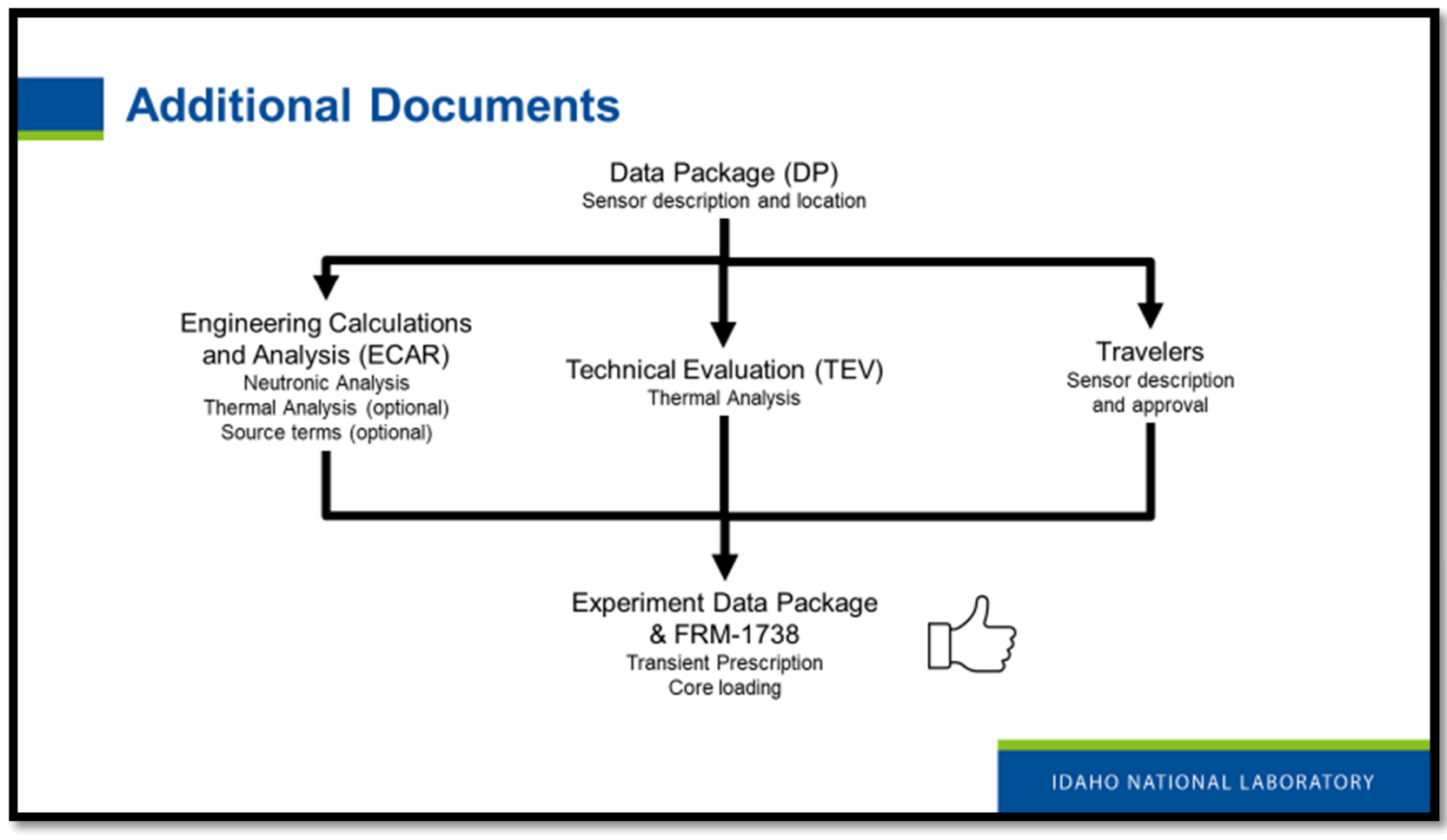




\section{Appendix B - Pictorial Overview Concurrent Testing Hardware and Layout in the TREAT Facility}

Kevin Tsai

Measurement Science Dept.

Idaho National Laboratory

\section{TREAT Concurrent Testing \\ Deployment Logistics}

\section{Layout Overview}

- Overview of sensor deployment for concurrent testing in the TREAT Facility

- Following slides per segment \# shown in figure below.
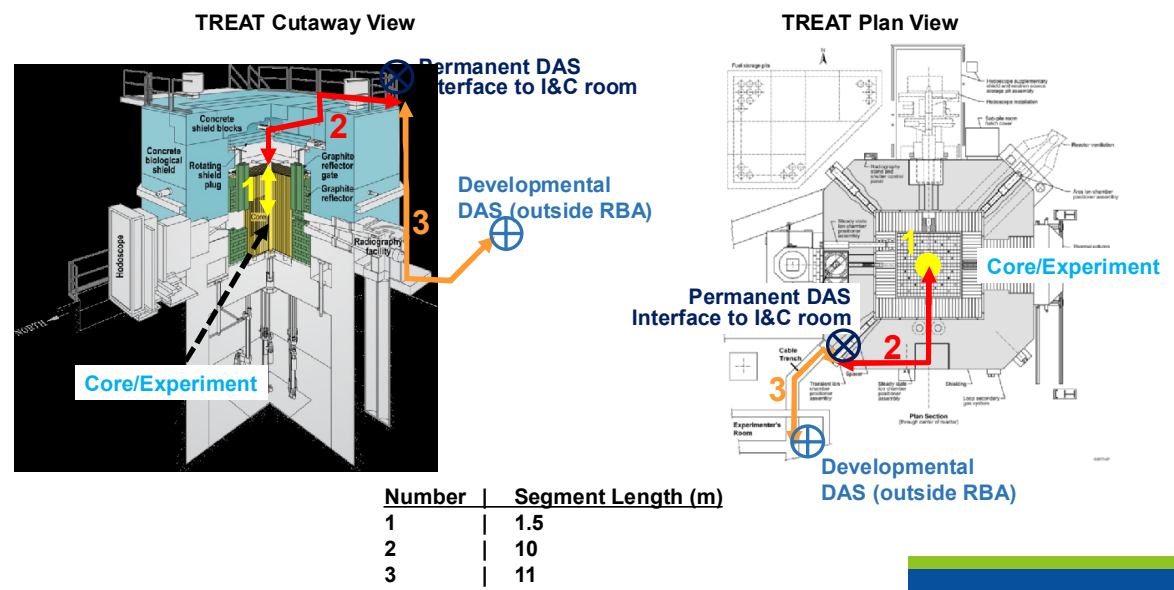


\section{Segment 1-TREAT hardware (Sensor Holders)}

- Used to suspend sensors in TREAT cooling channels.

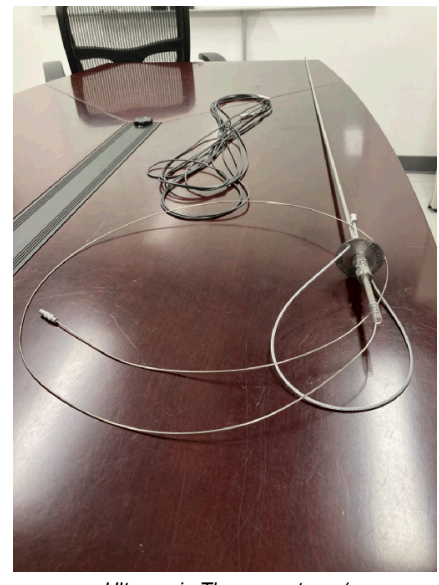

Ultrasonic Thermometer $w /$ TREAT hardware

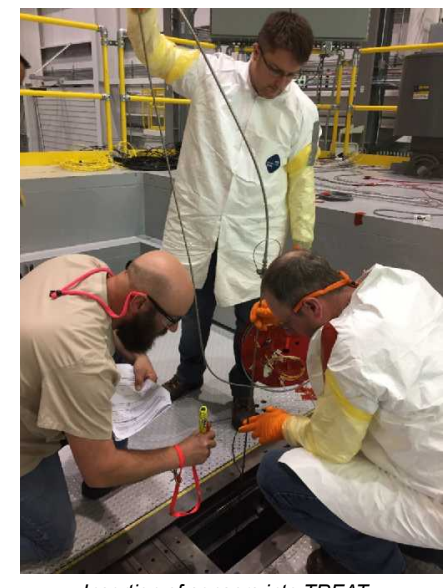

Insertion of sensors into TREAT cooling channels

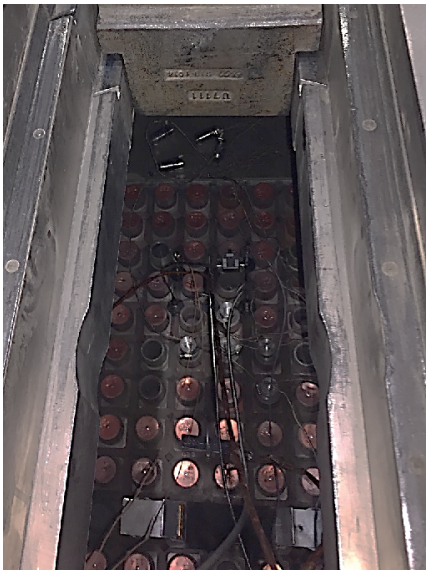

TREAT assembly top/down view $w /$ sensors inserted

\section{Segment 2-Cable Route to Reactor Top}

- Cables routed to reactor top for connection with Permanent DAS or preamplifiers
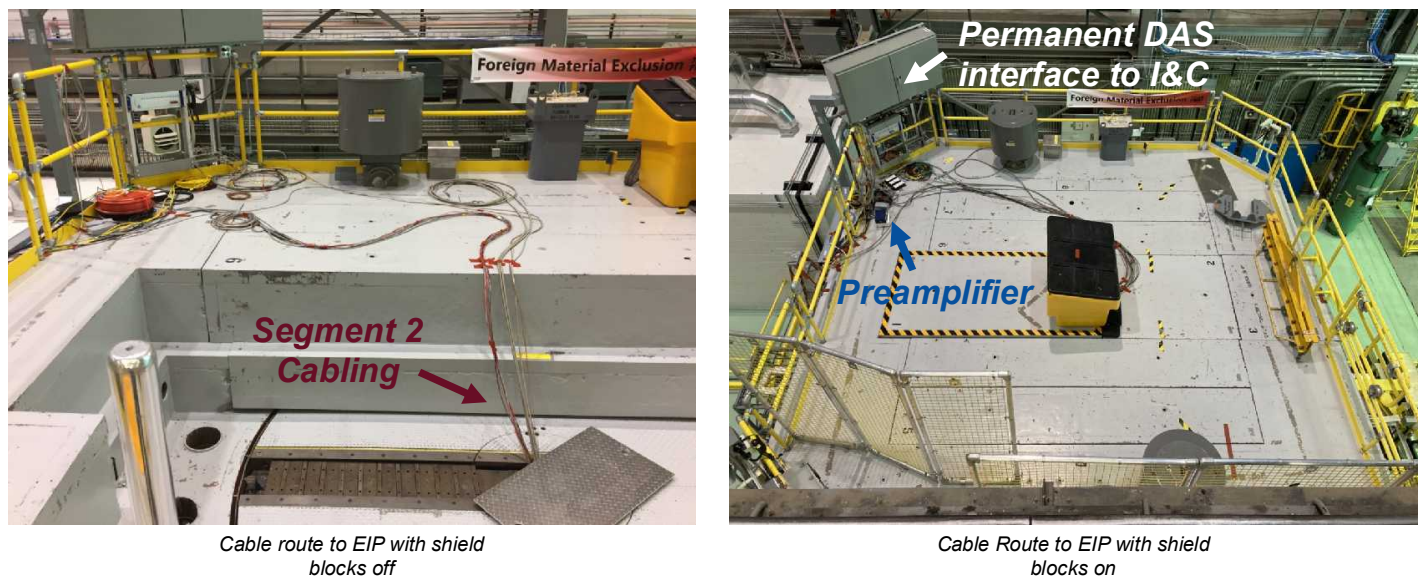


\section{Segment 3-Cable Route to Experimenter's Room}

- Cable route to the Experimenter's Room
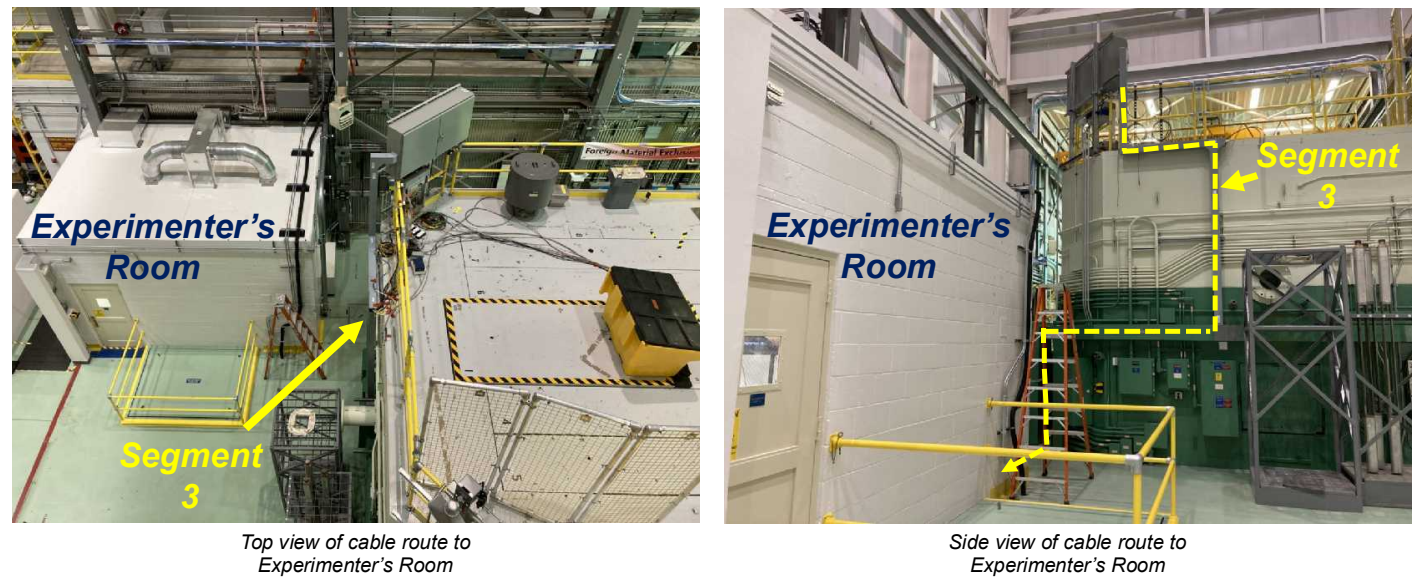

\section{Experimenter's Room \& Control Room}

- Cable route to the Experimenter's Room

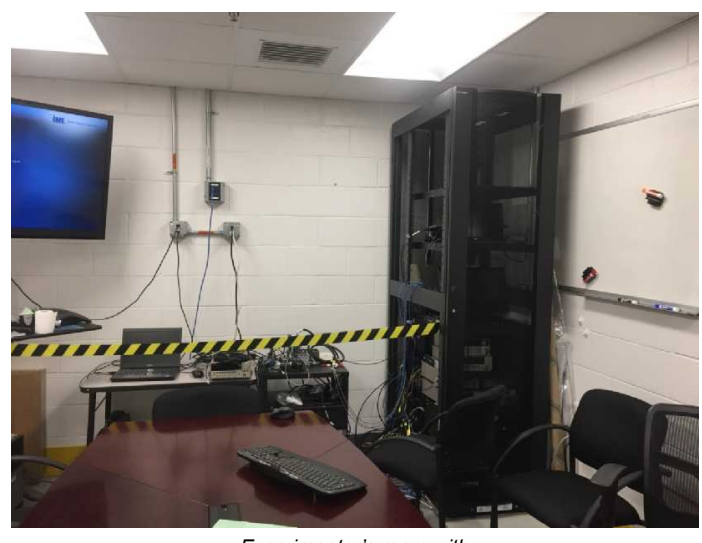
Experimenter's room with
Developmental DAS

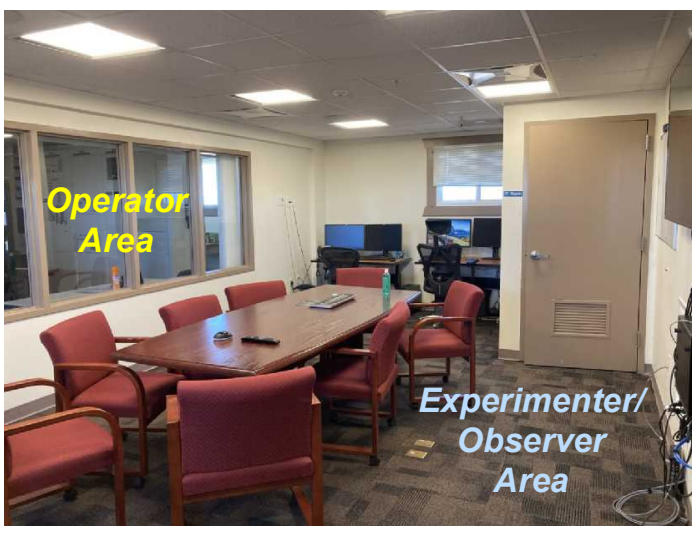

Control room 